\title{
Bajah's Interdisciplinary Model and the Conceptualization of Integrated Science in Nigerian School Curriculum
}

\author{
Jacinta A. Opara, PhD \\ Center for Environmental Education \\ Universidad Azteca, Chalco-Mexico
}

Doi:10.5901/ajis.2014.v3n7p96

\begin{abstract}
The aim of this paper is to examine how Bajah's model of integration reflects the true concept of integrated science. This paper is focused on the reasons that lead to this integration of learning experiences around a theme that will project the spirit of integration rather than mere putting together of subject matter from well defined disciplines. Integrated science presents the teaching of science in which concepts and principles are represented so as to express the fundamental unity of scientific thought. To teach any subject effectively, one must know what the subject is all about and for what purpose the subject has been introduced into the school curriculum. It represents the foundation stone for subsequent teaching in the sciences. It is devised and presented in such a way that pupils who may wish to pursue a science related career in life and general introduction to the sciences for others who may wish to pursue either humanities based or vocational inclined studies. Thus success or failure of integrated science teaching at this introductory stage is therefore very important. To have a balance introduction to science a solid foundation in integrated science is needed to equip the pupils for successful science careers thereby indirectly contributing to the much needed scientific and technological advancement of the global community.
\end{abstract}

Keywords: Bajah Model, Learning, Teaching, Science Education

\section{Introduction}

According to J.D.Arbon (1972) 'integration' when applied to science courses, means that, the course is devised and presented in such a way that, students gain the concept of the fundamental unity of science; the commonality of approach to problems of a scientific nature, and are helped to gain an understanding of the role and function of science in everyday life and the world in which they live. He added that, the integrating principles are intended to produce a course which;

1) is relevant to student needs and experiences

2) stresses to fundamental unity of science

3) lays adequate foundations for subsequent specialist study and

4) adds a cultural dimension to science education.

In other words, integrated science has been offered as a way to increase scientific literacy, the processes of science, increase interest in science, meet learners needs, maintain flexibility and show the relationship of science and society.

Khabele (1975) drew attention to the UNESCO publication in which integrated science was defined as an approach to the teaching of science in which concepts and principles are represented so as to express the fundamental unity of scientific thought and avoid premature or undue stress on the distinctions between the various scientific fields. An integrated science course eliminates the repetition of subject matter from the various sciences and does not recognize the traditional subject boundaries when presenting topics or theme.

\section{Rationale for Integrated Science}

In spite of the above, proponents of the single subject disciplines perceive integration as 'an undesirable trend, if not a vain hope'. They argue that, the separate study of biology, chemistry and physics as scientific disciplines is necessary to understand the content and methodology of each, and that attempts at integration present an erosion of intellectual integrity. Furthermore, they also maintain that it is impossible to devise an integrated science scheme in which the separate science disciplines are not recognizable. Notwithstanding arguments for and against integrated science, the 
Science Teachers Association of Nigeria (STAN) through the activities of its curriculum development committees decided to embark on integrated science course for the three years of the secondary schools in Nigeria.

The use of the integrated approach to science teaching arouse out of the need to make science teaching more meaningful and relevant to the students. This explains why the first generation of integrated science programs, the inquiry approach to learning was adopted. In addition, what was learnt as well as the materials used for classroom activities was as the material used for classroom activities were derived from the learners' immediate local environment. Since the introduction of science education reforms that culminated in the adoption of the integrated approach to science teaching in the United States of America, many countries have adopted the approach.

However, the philosophical arguments are based on the commonalities of all science or all science disciplines in relation to scientific concepts, principles, values attitudes and science processes as well as in relation to the interdisciplinary nature of real life problems to be tackled through science. Science should therefore be presented to pupils in a unified or holistic fashion so as to reflect these opportunity of learning science in multiple contexts. The claim that this facilitates transfer of knowledge, skills and techniques learnt in the science classroom to wider life outside it, forms one of the bases of ths pedagogical arguments.

There is also the practical need to avoid duplication of efforts since in the disciplinary approach; a topic may be treated in more than one discipline. Moreover, with the ever increasing explosion in scientific knowledge, what a student is required to learn in a disciplinary science is ever increasing. Hecht (1986) argues that if the integrated approach which necessarily incorporates the inquiry method of learning is adopted, students will be able to acquire fundamental insights which will serve as valuable reference point long after leaving school.

However, there are those who oppose the adoption of integrated science programmes for the practical reasons that quite often, most science teachers see themselves as disciplinary scientists and may not have the confidence to cross the boundaries of the other science disciplines, they are not trained in. some others oppose science as a unity approach from the viewpoint that it does destroys some of the unique characteristics of the disciplinary science (Avison, 1980). Nevertheless, the success of integrated science programmes (Haggis, 1980) as well as some disciplinary programmes such as the Physical Science Study Committee (PSSC), Chemical Education Material Studies and the Nuffield Science Projects which stress the inquiry approach to learning programmes encourages one to propose that science education in integrated form be made an integral part of compulsory general education in Nigeria secondary schools.

\section{Conceptual Framework for Integrated Science Education}

The success of first generation integrated science programmes assured their popularity. Later concern of integrated science teaching came to be widened to larger issues such as effect of science on the environment and the social responsibility of science. According to Baez and Alles (1973) there is a growing awareness that the adoption of the integrative approach to school science throughout secondary education could serve the realization of the goals of general education better. This is more so when the concern of science teaching is widened to include the ability to solve real problems.

The framework on which science education is built hinges on three areas as follows inquiry, concern and the ability to solve real problems. The spirit of scientific inquiry revolves around curiosity, while concern for others is associated with compassion which grows out of accumulated sets of attitudes acquired through participation in the scientific enterprise. Since the people are capable of logical and rational thinking Levis (1979), they are also idealistic and caring people; it is probably at this stage of their lives that concern and compassion for others can be imbued. In addition, they can be made aware of the doctrine of social responsibility and morality in science.

The ability to solve real problems means competence (Baez and Alles, 1973). Indeed, solving problems require making value judgments and taking decision. This in turn involves making choices considering the complex interaction of science and technology on one hand and society, culture and environment on the other. The exercise of choice in relation to scientific activities is an act of great responsibility. The three concepts, curiosity, compassion and competence are inextricably linked with each other. Moreover, they constitute important aspects of the general education of the individual. Incorporating them into an integral science programmes for the schools are very important.

\section{Bajah's Model of Integration Revisited}

Integrated science requires a concise description of its unique aspects in order to clarify how integrated science differs 
from non- integrated science. To underscore this point, certain characteristics of integrated science against those of nonintegrated science are stated as follows:-

\begin{tabular}{|l|l|l|}
\hline s/n & characteristics of integrated science & characteristics of non-integrated science \\
\hline 1 & Traditional subject matter boundaries are phased out & Individual identity of physics, chemistry and biology are maintained \\
\hline 2 & The course usually last for 2 or 3 years and is sequential & The course usually last for 3 or 4 years and is sequential \\
\hline 3 & The sequence tries to avoid duplication of content & Duplication of topics unavoidable in some cases e.g electrolysis \\
\hline 4 & The course usually serves as general education function & The course usually serve a specialist's education function \\
\hline 5 & $\begin{array}{l}\text { The course is organized around a selected unifying theme } \\
\text { or topic }\end{array}$ & $\begin{array}{l}\text { The course is not organized around a theme which unifies } \\
\text { individual subjects }\end{array}$ \\
\hline
\end{tabular}

According to Bajah (1983), integration of learning experiences around a theme will project the spirit of integration rather than mere putting together of subject matter from well defined disciplines. He gave examples as follows:- Integrated science programme, its unifying theme, LIFE, ENERGY, MATTER, and SOCIETY (LEMS). The general theme can form the basis of building up four modules. A module in this respect can be defined as a learning package. There could then be an interplay of ideas from physics, chemistry and biology relating to the central theme in the module. What will be significant in this approach is the fact that, each module will deal with a theme which can then have other sub-concepts. Any teacher who takes up module will find it hard to isolate certain areas as belonging to some subject discipline because the central theme will always remain. He developed the modules of LIFE, ENERGY, MATTER, and SOCIETY as follows:-

\section{Module on Life}

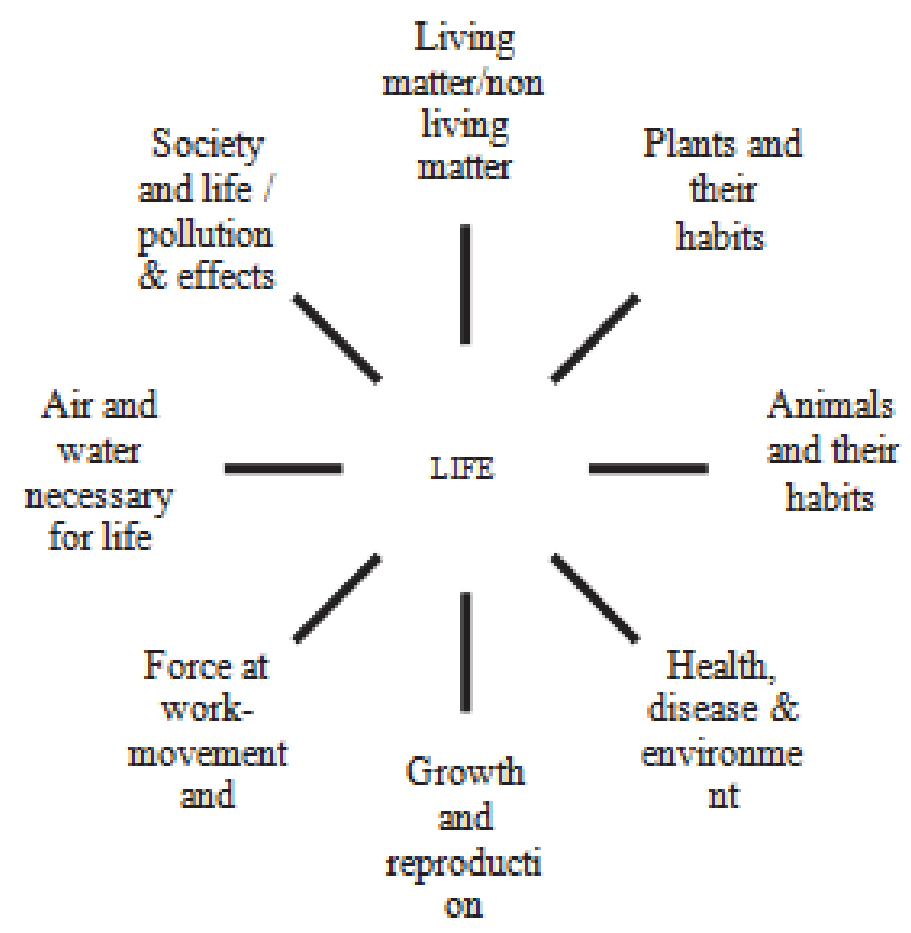


Module on Energy

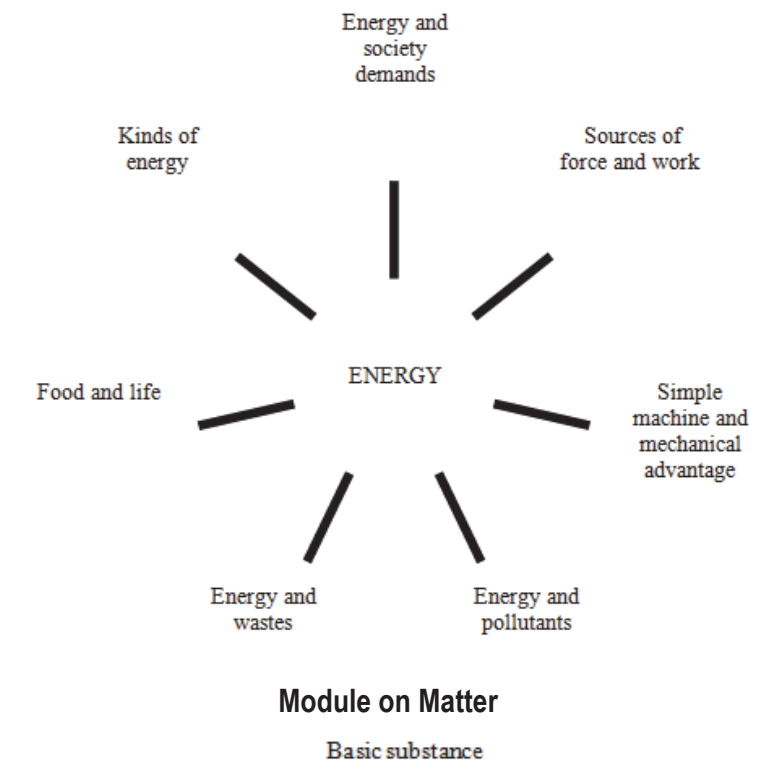

Behavior of
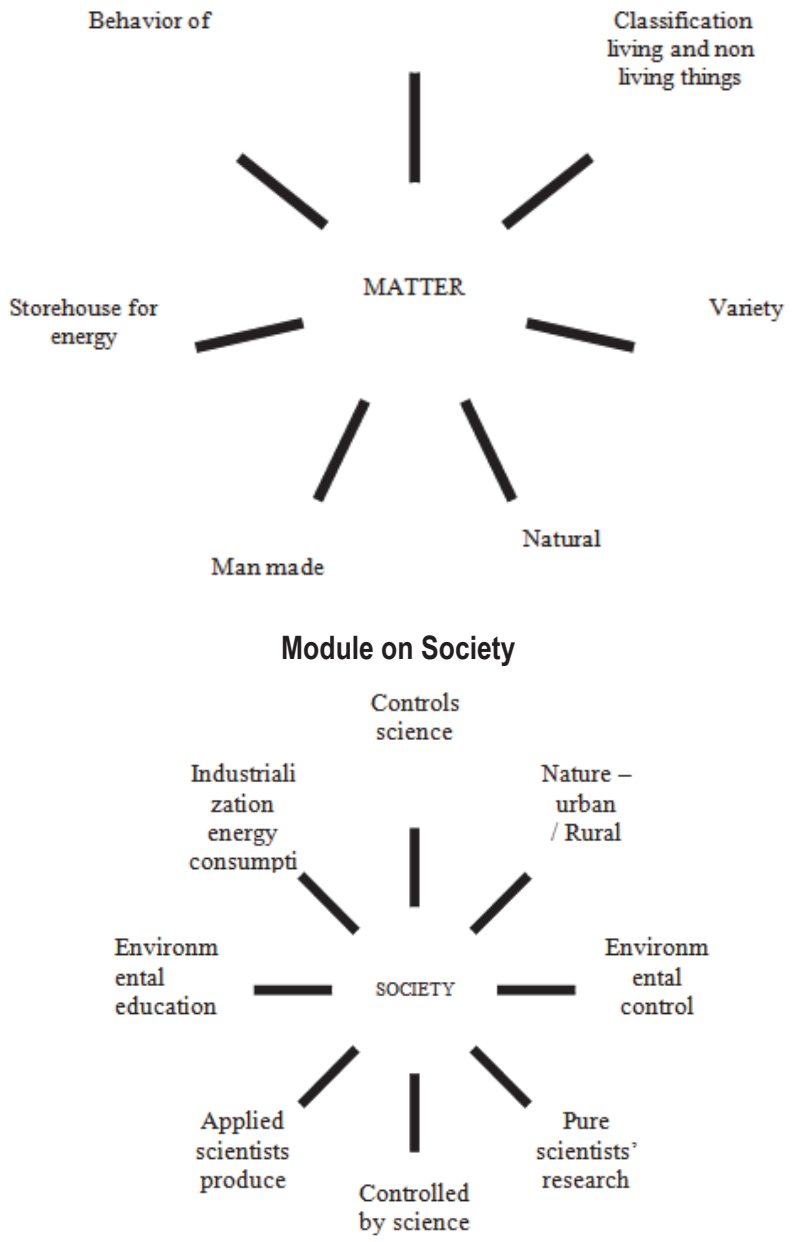


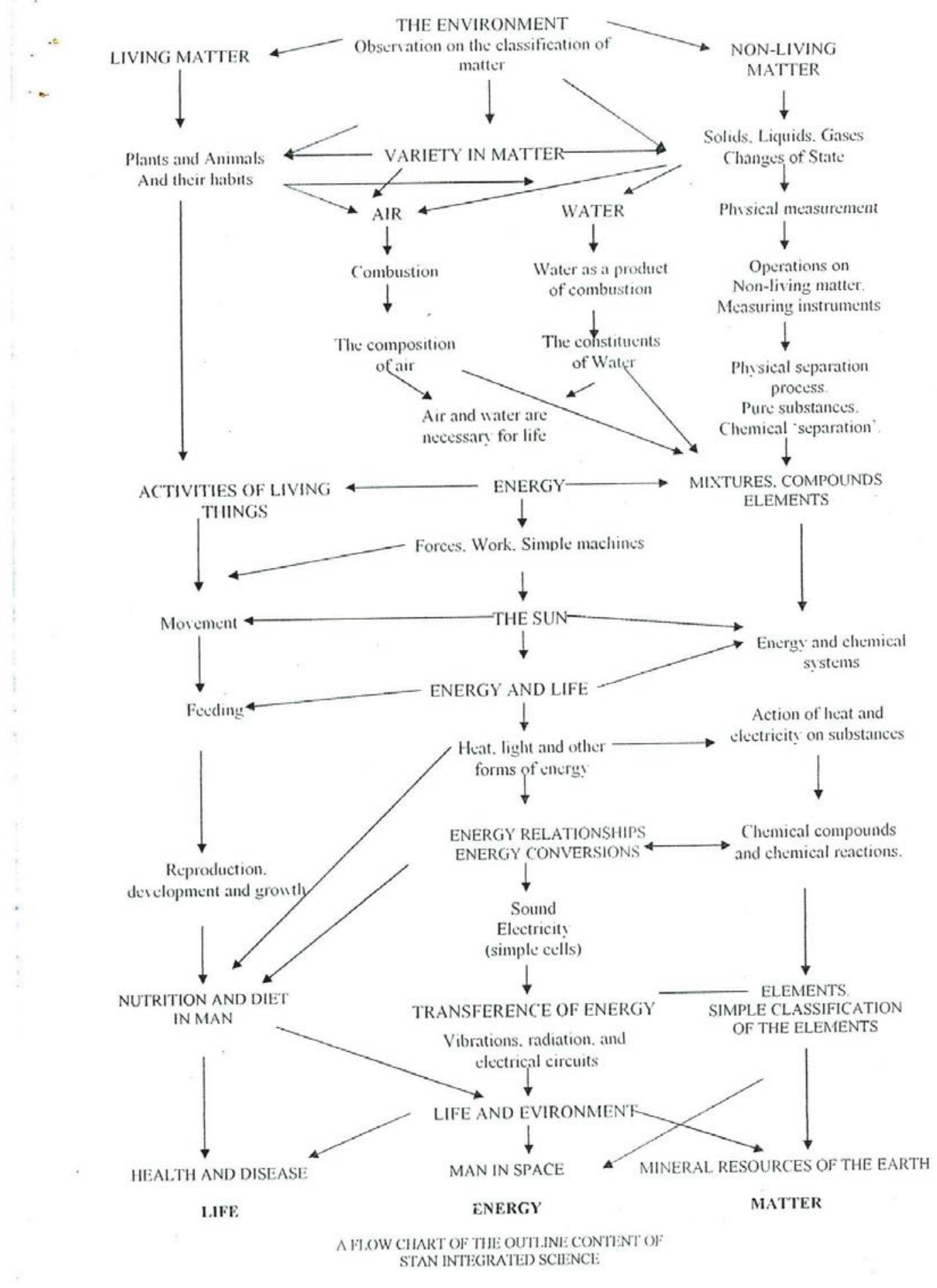

\section{Popularity Factors of Integrated Science}

The concept of integrated science has now been fully well established in most countries. The reasons for the popularity of integrated science can be attributed to many factors but of particular interest are those aspect identified by Haggis and Adey in their review of integrated science education worldwide. These factors are:-

1) Integrated science education is a rapidly developing and expanding field; 
2) There is a worldwide movement to introduce science into primary school education

3) There is a rapid and widespread development of integrated science education at the lower secondary level

4) Much greater attention is now being paid to the training and re-training of teachers for integrated science

5) There is a trend towards greater social relevance in integrated science courses

6) An emphasis is now being placed on environmental issues in integrated science courses

7) In integrated science courses in science and technology education are now being developed

8) The scope of integrated science courses is now being extended

9) Attempts are being made to inter-relate integrated science courses with other curriculum areas

10) Much more attention is being given to evaluation in science education

11) In the design of integrated science courses, the results of educational studies and research are being applied.

All the above factors make integrated science worthwhile not only in the developed countries but also in the developing third world countries.

\section{Conclusion}

With the increasing societal complexity arising from scientific and technological development, the nation will feel more than ever before the need for enhanced scientific literacy and the adaptive capacity of the individual and society. This need is best realized through science education programmes which are integrative in nature are available to all Nigerian even in the two sub-levels of secondary education. Such programmes must necessarily be part of compulsory general education; their goals are expanded to meet the criteria of social relevance, social responsibility and morality in science and competence in solving real problems.

\section{Acknowledgement}

This work received comments from some anonymous scholars. It was supported in part by a grant from European School Science Project.

\section{References}

Arbon, J.A (1977). A study of the concept of integrated science subjects in secondary schools, cited by Cohen in New Trends in Integrated Science Teaching vol. iv Paris: UNESCO

Avison, J. (1986) Keep physics in schools. Physics Education 21(3) 143-144

Baez, A.V. and Alles, J (1973). Integrated science teaching as part of general education. Looking ahead. In Richmond, P. E (ed). New trends in Integrated Science Teaching. Paris: UNESCO Press. 2, 167/175

Bajah, S.T (1983). Teaching integrated science creatively. Ibadan: University Press

Hecht, K (1986). Teaching national science: An integrated approach. Physical Education 21(5)

Haggis .S (1980). Development of integrated science worldwide :The past ten years. In Alonge E.I proceeding of the inaugural conference of the forum of African school science education (FASE) at University of Lagos. Lagos $25^{\text {th }}-30^{\text {th }}$ August.

Khabele, P.E. (1975). Secondary school integrated science: A modern approach to science education. STAN Journal. 13(2) 